\title{
On Talents Education of IP Cultural Industry Based on Market Demand
}

\author{
Ying TONG ${ }^{1, a^{*}}$, Si-Si $X U^{2, b}$ \\ ${ }^{1}$ Ningbo Dahongying University, Ningbo, Zhejiang, 315175, China \\ afreshying@126.com, b411492410@qq.com
}

Key words: Market demand, IP cultural industry, Talent quality, Education paths.

\begin{abstract}
For talents education, the design of object, process and evaluation have to be adaptable to the development of society, economy and culture. Nowadays, the economy development has stepped into "new normal" phase, together with the adjustment of national strategy, and driven by inner economic regularity, national cultural consumption has been on the rise and the development of cultural industry has entered into a golden age. Recently, "IP rush" has become the engine and energy of cultural industry development. Hence, it is an urge to have an exploration of talents education of IP cultural industry. The paper, based on a detailed analysis of backgrounds of market demand and driving factors for talents education, puts forward that through building cooperative education mechanism, defining education content, enhancing platform construction and perfecting evaluation system, talents' intellectual property literacy, professional and compound knowledge, the capability of all-media operation and creative ability should be improved.
\end{abstract}

\section{Introduction}

In the new era, under the circumstance of continuous support for cultural development from the national government and cultural turn in the capital market, the innovation and development of cultural industry has been promoted through the assistance of internet, big data, cloud computing and mass media, etc. The competitiveness of cultural industry lies in its intellectual property, which actually refers to the green resources bearing strong cultural symbolism, far-reaching influence and commercial values and finally are transferred to cultural products or services, which can attract vast population of consumers. Therefore, the IP cultural industry refers to a series of cultural activities embarking on realizing potential cash ability of scripts, stories, concepts, images, even words and behaviors which are of cultural, economic, and market values through being shown in films, TV series, cartoons, computer games, music and so on, forming various industrial formats and integrated industrial chain.

Human resources are the key factor deciding enterprises' occupation of the market. The types of talents as well as their quality need to adapt to the needs of the society, avoiding separating from the development of social and industrial trend, otherwise it would cause the wasting of resources and lead to unbalanced structure of talents supply and demand. Meanwhile, cultural industry promotion is the basis for maintenance and inheritance of Chinese culture, construction of cultural confidence, and cultural spreading while talents are the source of cultural innovation and creation. "Recently, due to the pushing of mass culture, the involvement of capital markets and commercial operation, the driving force of IP transformation is being raised and multiple cultivation of IP values has become a popular bushiness model of cultural industry." [1] Therefore, it is of great necessity to have researches into the developmental features and trend of IP cultural industry, and at the same time readjusting the education conception, contents and models for cultural industry talents, which can solve the problem of negative linkage effect caused by short supply of talents and speed up the development of cultural industry.

\section{Driving Factors for Talents Education of IP Cultural Industry--Labor Market and Industrial Demands}

In 2015, "Supply-side Structural Reform” has been put forward during the the Central Economic Working Conference in China, and education of IP cultural industry talents is in need of the 
structural reform in case that there would be "structural shortage" of talents during industry transformation and upgrading. Presently, the gap between the need of labor market and talents training tends to be much bigger, which would have bad impact on the development of economy. In the long history of Chinese culture, there exists abundant cultural resources. How to integrate those resources into the cultivation of cultural industry depends on talents' intelligence. Since 2015 the number of IP has shown a rapid growth and the price of IP is increasingly higher than before, and there is an urgent requirement for cultural talents. Thus, it is imperative to train a group of talents for IP cultural industry according to the present labor market.

The education of IP cultural industry talents can contribute to intension-type development of cultural industry. In a liberal market economy, the productive factors have been reallocated, and the consumers' preference varies from each other. Cultural products and services have continuously taken market shares, and its scale and quantity is experiencing fast development. How to activate the cultural resources and infiltrate them with creativity? How to generate a developmental leap from the quantity to the quality of cultural industry? To solve the above two questions, high-level talents are in necessity. On Nov. $4^{\text {th }}, 2016$, Fan Zhou, the director of the Cultural Industry Expert Committee of Chinese Cultural Ministry, said " People are impressed by Shenzheng(a costal city in the southeast of China, which was ever called as "cultural desert", but now the revenue scale of cultural industry is more than one trillion )" instead of Shanxi (a city located in the northwest of China which has lots of Chinese cultural relics)." [2] It is mainly attributed to the different numbers of cultural talents.

\section{The Requirement for Talent Quality of IP Cultural Industry based on Market Positioning}

The talent quality refers to a stable characteristic, thinking ability and potential competence that a person has, which influenced by knowledge learning, social practice and also innate physiological basis. Special Attention to "social adaptability and individualized development "[3] should be paid to talents cultivation. For IP cultural industry talents, they should gain special abilities except for general abilities, such as physical, conceptional, cultural and psychological qualities. The special abilities are stated as follows:

\section{Cultural Sense of Intellectual Property}

The cultural quality is the social awareness produced from human beings' spiritual world. Restricted by social norms, a person, through experiencing the society, forms his/her unique psychological and personality model which can express their subjective ideology of recognizing and reconstructing the world. IP cultural industry, involved with the originality of cultural resources, unlike patented invention and software copyright, puts emphasis on emotional sustenance, experience and the identification of cultural values rather than applied function of products. Basically, IP cultural industry talents should have strong cultural sense of intellectual property, which consists of consciousness of intellectual property, theoretical knowledge of intellectual property, creative ability of intellectual property and operative ability of intellectual property.

\section{Knowledge Structure of the Professional and the General}

IP cultural industry is characterized by strong application and interdisciplinarity. On the one hand, IP cultural industry talents not only need to receive systematic professional training including Management Science, Applied Economics and Communications, etc. to grasp profound professional knowledge and skills, by which they can do well with content creation, administrative operation and business operation. On the other hand, because IP cultural industry is a light-asset industry different from heavy-asset industry, which has less fixed investment and can be easily integrated with other industries, and the profit of IP cultural industry is much higher. IP cultural products and services provide comprehensive and immersive experience for consumers, which proposes the demands for multiple talents' qualities including theoretical and practical knowledge, the ability of resource integration, cooperation, planning and so on. Only if IP cultural industry talents have solid professional and general knowledge can they ordinate and lead the development of IP cultural 
industry.

\section{Capability of All-Media Operation}

With the rapid development of science and technology, traditional form of one media communication has been changed into that of multiple media spreading in the new media age, which facilitates diversified conversion and utilization of cultural IPs. Superior and popular cultural IPs can be cultivated twice and reused repeatedly, which deepens the concept of cultural exchange, broadens the values of industrial chain and increases profit channels. Meanwhile, one of IP cultural industry advantages is its high level of user's engagement, which means fans play important roles in its development. "Fans are the target consumers of media products who participate in and give feedback to media communication and also can be the sources or creators of the contents ."[4] As a consequence, industrial talents should keep sharp insight into quality cultural IPs and market segmentation.

\section{Creativity and Innovative Thinking Ability}

“Although 'design thinking' is massively applied in contemporary design and engineering practice, it is applicable to various subjects and industries" [5] Culturally-designed products can inspire consumers' desire for cultural experience. Cultural products express cultural elements but also are related to consumers' appreciation and admiration of the culture. For example, the world famous “Transformers", "Star Wars" and the others alike all reflect consumers' recognition of American heroism. In 2016, Tencent, an famous internet platform in China, held a competition named "NEXT IDEA" which motivated a large amount of talents to have a deep dig into cultural IPs. The design of "facial expressions" and "mobile game" with classical IP images in National Palace Museum being the prototypes encouraged competitors to give a full play to their creative thinking ability to "renew the tradition". They have to reconsider the connotation of traditional culture and redesign with individual understanding and aesthetic experience. "Under the background of open innovation model, the cultural IP is not only to be considered as the outcome of scientific research but also the decisive factor during innovation process, which can ensure the uniqueness of knowledge and explore ways to develop market, potential consumers and precious knowledge. "[6] Accordingly, creativity and innovative thinking ability is being a part of talents' quality.

\section{The Object of Talents Education for IP Cultural Industry and its Paths: From Macro to Micro}

Based on scientific epistemology and the above analysis of social and market needs, the author finds it is of great significance to construct a team of IP cultural industry talents, which is a detailed index showing culture power of the state. The specific strategies are as follows: establishing cooperative education mechanism, renewing education contents, enhancing the construction of training platforms and improving talents appraising system.

\section{Collecting Power from the Government, Enterprises, Colleges and Research Institutes to Develop Talents' Ideological Awareness}

Naturally, the subjective consciousness and thoughts and perceptions of talents provide premises for their quality cultivation. Cultural IP is the creation and innovation of knowledge, so the talents should firstly be aware of the importance of cultural intellectual property psychologically and emotionally.

The government, enterprises, colleges and research institutes should shoulder respective responsibilities to instantly inform the talents of relevant policies about cultural intellectual property, creating good environment for the the development of cultural intellectual property. The education organizations should enhance the construction of hidden culture in in our society and encourage the talents to participate in relevant training seminars, through which the talents can also exert influence on companions and even social groups. Educators should keeping renewing the knowledge on intellectual property and incorporate them into education contents, helping the talents form conception of respecting originality and protecting individual achievements, and also internalize the 
cultural awareness inwardly and externalize the cultural intellectual property outwardly through their behaviors.

\section{Paying Attention to the Hierarchy of Education Contents}

"The nature of IP can be defined as cultural capital according to Bourdieu."[7] The industrial chain of IP cultural industry can be divided into three different periods. In each period, talents' special quality is emphasized accordingly. During the initial period of industrial chain, creating IP is the main developmental target. On the basis of intelligence inputs, cultural IPs in the market are of varying quality, whether the enterprise can make a profit or not is of great uncertainty. During the middle period of industrial chain, those IP-cultivating companies, for example, online literature platforms, publishing houses, film companies and game companies try to restructure the original IPs and sell them with more costs, and the competition between those companies is much orderly while hoarding and wasting of IPs is prevailing. During the terminal period of industrial chain, the enterprises and business groups develop IPs repeatedly, through being shown by film, TV series, dramas, cartoons and games to inspire the fans' emotional resonance, which leads to high additional values of IPs.

Hence, the education models of talents should be designed accordingly. The contents, curriculum setting and training time should be arranged differently. During the initial period of industrial chain, for those creative talents, the abilities of collecting, compiling, recording and writing should be emphasized; During the middle period of the industrial chain, for those management personnel, the abilities of operation, promotion and decision-making, and governance should be emphasized. During the terminal period of the industrial chain, for those skilled talents, the abilities of technical application, information processing and designing should be emphasized.

Meanwhile, in view of the close connection between IP cultural industry and other industries, the talent should have a through and profound understanding of production process and industry ecology of IP cultural industry and also a sound knowledge system of culture, laws, psychology and sociology, etc.

\section{Enhancing the Construction of Education Platforms to Cultivate Media Talents}

With the advent of omnimedia era, various medias interact with each other, and media convergence dominates media development. Under the circumstance of ever-changing marketing environment and the development of IT, the education platforms should be increasingly constructed. Firstly, practice platforms of digital media enable talents to be familiar with IP cultivation, IP creation, and IP operation. Secondly, during different periods of education, it is necessary to teach students how to simulate media technologies during classroom learning, internship or training duration, with different education organization sharing data resources, which can help talents develop their abilities of all-media manipulation.

\section{Taking Creative Ability as the Main Evaluating Index to Improve Talents Appraising Mechanism}

Innovation is the core and endogenetic drive for IP cultural industry, for which the creation of cultural contents and forms of cultural production are rather significant. Timothy Taylor, a professor of Stanford University, ever put forward that the critical point of innovation lies in talents' competence of making profits from the investment of research and development, which is called 'appropriability' by economists. If the inventors and manufacturers do not gain much from their endeavor. They would not make innovation.[8] Therefore, the interaction between economic interest and innovation is rather close.

During the process of talents education, innovative ability and creative thinking ability should be given priority. Firstly, the education contents need to be professional and forefront, which helps talents instantly capture market trend and industrial development. Secondly, reducing cramming while adopting interactive, heuristic and exploitative methods to inspire talents' creation. Thirdly, paying attention to practice periods, during which talents' industrial skills need to be emphasized, for instance, the abilities of distributing resources, personnel assignment and work coordination 
should be highlighted. Especially attaching great importance to education process and evaluation of talents, with factors of the post competency and social influence as the criterion for talents selection. Gathering evaluation data from the government, enterprises, colleges and social groups to keep dynamic evaluation of talents, and establishing social feedback mechanism. As a result, Readjusting education conception and models at regular intervals.

\section{Conclusion}

As the above mentioned, there is a close relationship between the education of talents and labor market. The imbalanced structure of talents supply and demand causes increasing labor cost to enterprises as well as structural unemployment in the society. The "IP rush" in cultural industry has been pursued by the capital and the public, which gives rise to the market demand for industrial talents. How to cultivate industrial talents who are suitable for the present cultural and economical development, and avoid homogeneity of talents' qualities to achieve the excellent interaction between the industry development and talents supply is the current question that the government, enterprises and companies and other education organizations need to focus on.

\section{Acknowledgement}

This research was supported by the Art Project of the National Social Science Foundation of China(Granted No. 16BH132), the Education and Science Programming Project of Zhejiang(Granted No. 2018SCG089) and Civil Policy Planning Project of Zhejiang(Granted No. ZMYB201724 ).

\section{References}

[1] Chen Weichao. The Core Logic and Innovative Strategies for IP-centered Model of Digital Publishing Industry, Publishing Research[J]. 2017(4):25-28.

[2] Fan Zhou: The Cultivation of Cutural IPs is up to the Talents Instead of Museum Collections, information on http://www.xmyy.com/news-395015.html, 2016.11.05.

[3] Junrui L., Yan W. (2011) Talk about Local University Talent Training and the Demand of Economic Social Development. In: Lin S., Huang X. (eds) Advances in Computer Science, Environment, Ecoinformatics, and Education. CSEE 2011. Communications in Computer and Information Science, vol 216,P242-248.

[4] Gong Xianjing. Research on the Relationship between the Characteristics of "IP” Industry and the Applied Talents Training Mode of Art Colleges, Journal of Huangshan University[J], 2016(6):137-140.

[5] Pradeep Sahay, “Design thinking in talent acquisition: a practitioner's perspective”, Strategic HR Review[J]. 2014(4):170-180 .

[6] Paola Belingheri, Maria Isabella Leone, "Walking into the room with IP: exploring start-ups' IP licensing strategy”, Management Decision[J]. 2017(6):1209-1225.

[7] Xiang Yong \& Xiang Xiaoqing. Field Resonance: Strategies for Crossover Development of IP values of Network Literature. Modern Communication[J]. 2016(8):110-114.

[8] Timothy Taylor. The Instant Economist: Everything You Need to Know About How the Economy Works[M]. New York: Plume, 2012. 